\title{
Repeated Administration of Bone Marrow- Derived Cells Prevents Disease Progression in Experimental Silicosis
}

\author{
Miquéias Lopes-Pacheco a,b,c Debora G. Xisto ${ }^{a, b} \quad$ Felipe M. Ornellas ${ }^{a}$ \\ Mariana A. Antunes ${ }^{b}$ Soraia C. Abreu ${ }^{b}$ Patricia R. M. Rocco ${ }^{b}$ Christina M. Takiya \\ Marcelo M. Morales ${ }^{a}$ \\ aLaboratory of Cellular and Molecular Physiology, Carlos Chagas Filho Biophysics Institute, Federal \\ University of Rio de Janeiro, 'baboratory of Pulmonary Investigation, Carlos Chagas Filho Biophysics \\ Institute, Federal University of Rio de Janeiro, CLaboratory of Cellular Pathology, Carlos Chagas Filho \\ Biophysics Institute, Federal University of Rio de Janeiro, Rio de Janeiro, Brazil
}

\author{
Key Words \\ Cell therapy • Inflammation • Fibrosis • Elastic fiber • Silicosis
}

\begin{abstract}
Background/Aims: Bone marrow-derived cells (BMDCs) reduced mechanical and histologic changes in the lung in a murine model of silicosis, but these beneficial effects did not persist in the course of lung injury. We hypothesized that repeated administration of BMDCs may decrease lung inflammation and remodeling thus preventing disease progression. Methods: One hundred and two C57BL/6 mice were randomly divided into SIL (silica, 20 $\mathrm{mg}$ intratracheally [IT]) and control (C) groups (saline, IT). C and SIL groups were further randomized to receive BMDCs $\left(2 \times 10^{6}\right.$ cells) or saline IT 15 and 30 days after the start of the protocol. Results: By day 60, BMDCs had decreased the fractional area of granuloma and the number of polymorphonuclear cells, macrophages (total and M1 phenotype), apoptotic cells, the level of transforming growth factor (TGF)- $\beta$, and types I and III collagen fiber content in the granuloma. In the alveolar septa, BMDCs reduced the amount of collagen and elastic fibers, TGF- $\beta$, and the number of M1 and apoptotic cells. Furthermore, interleukin (IL)- $1 \beta$, IL-1R1, caspase-3 mRNA levels decreased and the level of IL-1RN mRNA increased. Lung mechanics improved after BMDC therapy. The presence of male donor cells in lung tissue was not observed using detection of $Y$ chromosome DNA. Conclusion: repeated administration of BMDCs reduced inflammation, fibrogenesis, and elastogenesis, thus improving lung mechanics through the release of paracrine factors.
\end{abstract}




\section{Cellular Physiology and Biochemistry}

Cell Physiol Biochem 2013;32:1681-1694

\begin{tabular}{l|l}
\hline DOI: $10.1159 / 000356603$ & (C) 2013 S. Karger AG, Basel
\end{tabular}

www.karger.com/cpb

Lopes-Pacheco et al.: Repeated Administration of Stem Cell Prevents Silicosis

\section{Introduction}

Chronic inhalation of silica particles leads to a persistent inflammatory process, formation of granulomatous nodules, and lung fibrosis. Silicosis is an occupational disease that causes respiratory failure due to reduction in the area of gas exchange and deterioration in lung function [1-3]. To date, there has been no effective treatment to minimize the development of this disease. Clinical treatment is based on controlling the symptoms and preventing complications [4].

Several studies have reported on the beneficial effects of bone marrow cell therapy in different models of lung injury [5-10]. In experimental models of lung fibrosis, bone marrowderived cells (BMDCs) were able to repair damaged tissue by modulating the inflammatory process and replacing damaged cells [3, 5-7].

In a previous study, we observed that in experimental silicosis, the early beneficial effects of BMDC therapy on lung inflammation and mechanics were transient [11]. Therefore, we tested the hypothesis that a protocol with repeated intratracheal administration of BMDCs could reduce the ongoing inflammatory and fibroelastogenic processes, thus improving lung mechanics. We explored the effects of repeated intratracheal administration of BMDCs on days 15 and 30 in a well-established model of silicosis. Lung mechanics, histology, apoptosis, morphometry, and humoral and cellular assessments of inflammation were analyzed. Remodeling was evaluated by assessment of collagen and elastic fiber deposition, transforming growth factor (TGF)- $\beta$, and changes in macrophage phenotype.

\section{Materials and Methods}

This study was approved by the Health Sciences Center Ethics Committee at the Federal University of Rio de Janeiro (CEUA-CCS-019). All animals received humane care in compliance with the Principles of Laboratory Animal Care formulated by the National Society for Medical Research and the Guide for the Care and Use of Laboratory Animals prepared by the National Academy of Sciences, USA.

\section{Animal preparation and experimental protocol}

A total of 102 mice (8-12 weeks of age) were used in this study. Seventy male mice were used as bone marrow donors. Thirty-two female mice were randomly divided into two groups: $\mathrm{C}$ group, instilled with sterile saline ( $50 \mu \mathrm{L}$ intratracheally [IT]) and SIL group, instilled with a silica particle suspension (20 mg/50 $\mu \mathrm{L}$ of saline) (particle size: 80\% between 1 and $5 \mu \mathrm{m}$; Sigma-Aldrich, St. Louis, MO, USA). These groups were then subdivided into two groups: mice that received saline (Sal) or BMDCs (Cell). Animals were treated with BMDCs $\left(2 \times 10^{6}\right.$ cells $/ 50 \mu \mathrm{L}$ of saline IT) 15 and 30 days after the start of the protocol (C-Cell and SIL-Cell groups) (Fig. 1).

\section{Extraction and culture of BMDCs}

BMDCs were obtained from the femur and tibia of male mice as previously described $[9,11]$. After the epiphyses were cut, the bones were centrifuged $(400 \times \mathrm{g}$ for $10 \mathrm{~min})$ and the bone marrow was collected. The cells were resuspended in Dulbecco's modified Eagle's medium (DMEM; Life Technologies, Grand Island, NY, USA) supplemented with 20\% fetal bovine serum (Gibco), 2 mM L-glutamine (Sigma-Aldrich), and antibiotics (penicillin/streptomycin) and plated in culture flasks $\left(10^{6} \mathrm{cells} / \mathrm{cm}^{2}\right)$. The following day, the supernatant was discarded and the adhered cells were washed with phosphate-buffered saline. Cells were re-fed with DMEM, which was changed every 2 days. On day 7, adherent cells were trypsinized and after Trypan Blue staining, they were counted in a Neubauer chamber for evaluation of viability.

\section{Lung mechanics}

Sixty days after instillation of saline or silica, the animals were sedated (diazepam $1 \mathrm{mg} / \mathrm{kg}$ intraperitoneally), anesthetized (thiopental sodium $20 \mathrm{mg} / \mathrm{kg}$ intraperitoneally), tracheotomized, paralyzed (vecuronium bromide $0.005 \mathrm{mg} / \mathrm{kg}$ intravenously), and ventilated with a constant flow ventilator (Samay VR15; Universidad de la Republica, Montevideo, Uruguay) using the following parameters: frequency, 100 


\section{Cellular Physiology and Biochemistry}

Cell Physiol Biochem 2013;32:1681-1694

\begin{tabular}{l|l}
\hline DOI: $10.1159 / 000356603$ & (C) 2013 S. Karger AG, Basel
\end{tabular}

Published online: December 13, $2013 \quad$ www.karger.com/cpb

Lopes-Pacheco et al.: Repeated Administration of Stem Cell Prevents Silicosis

breaths/min; tidal volume $\left(V_{\mathrm{T}}\right), 0.2 \mathrm{~mL}$; fraction of inspired oxygen, 0.21 . The chest wall was surgically removed and a positive end-expiratory pressure of $2.0 \mathrm{cmH}_{2} \mathrm{O}$ was added. After a 10-min ventilation period, lung mechanics were computed and at the end of the experiments (20-25 min), lungs were prepared for histology and molecular analysis.

Lung static elastance $(E s \mathrm{~s}, \mathrm{~L})$, resistive pressure $(\triangle P 1, \mathrm{~L})$, and viscoelastic/inhomogeneous pressure $(\triangle P 2, \mathrm{~L})$ were measured using the end-inflation occlusion method [12]. All data were analyzed using ANADAT data analysis software (RHT-InfoData, Inc., Montreal, Quebec, Canada).

\section{Histology}

Immediately after lung mechanics were assessed, heparin (1000 IU) was intravenously introduced into the vena cava and a laparotomy was performed. The trachea was clamped at end expiration, and the abdominal aorta and vena cava were sectioned, leading to a massive hemorrhage that quickly killed the animals. The left lung was isolated, frozen quickly by immersion in liquid nitrogen, fixed with Carnoy's solution, and embedded in paraffin. Three $4-\mu \mathrm{m}$-thick slices per lung were cut and stained with hematoxylin-eosin for lung morphometric analysis, or Weigert's resorcin-fuchsin method with oxidation for quantification of elastic fibers in alveolar septa and silicotic nodules.

For lung morphometric analysis, a reticle composed of 100 points and 50 lines (known length) coupled to the right eyepiece of a light microscope was used. The fractional area of granuloma and the total and differential cellularity of granuloma were determined by the point-counting technique [13] in 20 random non-coincident microscopic fields. A 20× objective lens was used to determine the fractional area of granuloma, and a $100 \times$ objective lens was used to assess the total and differential cellularity of granuloma.

Total number of macrophages (MØ) and subpopulations (M1 and M2), level of TGF- $\beta$, and type III and type I collagen fiber content were quantified separately in alveolar septa and granuloma after labeling by immunohistochemistry. Monoclonal antibody F4/80 rat anti-mouse (catalog no. MCA497, AbD Serotec) was used to label macrophages MØ. Macrophages M1 and M2 were labeled using polyclonal antibody inducible nitric oxide synthase (iNOS) rabbit anti-mouse (catalog no. Rb-9242, Thermo Scientific) and polyclonal antibody arginase-1 rabbit anti-mouse (catalog no. sc-20150, Santa Cruz Biotechnology), respectively. TGF- $\beta$ was detected using a rabbit polyclonal anti-pan-TGF- $\beta$ (catalog no. AB-100NA, R\&D Systems, USA). The extracellular matrix components were labeled with rabbit anti-mouse polyclonal antibodies to type III and type I collagens (catalog nos. 20141 and 20341, respectively; Novotec, France).

Antibodies were detected using a secondary antibody labeled with peroxidase from Nichirei Biosciences (Tokyo, Japan) (Histofine mouse MAX PO anti-rat and anti-rabbit) followed by the chromogen substrate, diaminobenzidine (liquid DAB; catalog no. K3468, Dakocytomation, USA). Thirty microscopic fields were randomly selected, avoiding vessels and bronchi, using a digital camera (Evolution, Media Cybernetics, Silver Springs, MD, USA) coupled to a light microscope (Eclipse 400; Nikon, Tokyo, Japan), and a computer with graphical interface software (Q-Capture 2.95.0, version 2.0.5; Silicon Graphics Inc, USA). High-quality images $(2048 \times 1536$ pixel buffer $)$ were captured after setting up and calibrating the program, using the $40 \times$ objective lens. The number of labeled macrophages was divided by the total number of cells per field. The area occupied by TGF- $\beta$ and collagen was divided by the total tissue area, and the results were expressed as surface density. The images were analyzed using Image-Pro Plus 4.5.1 software (Media Cybernetics).

\section{TUNEL assay}

DNA fragmentation associated with apoptosis was detected by terminal deoxynucleotidyl transferase (TdT)-mediated dUTP nick-end labeling (TUNEL), using an ApopTag peroxidase in situ apoptosis detection kit (catalog no. S7101, EMD Millipore, Billerica, MA, USA), according to the manufacturer's instructions. For quantification, 50 microscopic fields were randomly captured (25 in granuloma and 25 in alveolar septa) using a $40 \times$ objective lens. Positive nuclei results are expressed as the percentage of apoptotic cells.

Levels of interleukin (IL)-1 $\alpha, I L-1 \beta, I L-1$ receptor type $1, I L-1$ receptor antagonist, IL-10, metalloproteinase-9, TGF- $\beta$ and caspase- 3 mRNA

Central slices of right lung were cut, collected in cryotubes, quick frozen by immersion in liquid nitrogen, and held at $-80^{\circ} \mathrm{C}$. A quantitative real-time reverse transcription (RT) polymerase chain reaction (PCR) was performed to measure the relative levels of mRNA of IL-1 $\alpha$, IL-1 $\beta$, IL-1 receptor type 1 (IL- 


\section{Cellular Physiology and Biochemistry}

Cell Physiol Biochem 2013;32:1681-1694

\begin{tabular}{l|l}
\hline DOI: $10.1159 / 000356603$ & (C) 2013 S. Karger AG, Basel
\end{tabular}

www.karger.com/cpb

Lopes-Pacheco et al.: Repeated Administration of Stem Cell Prevents Silicosis

1R1), IL-1 receptor antagonist (IL-1RN), IL-10, metalloproteinase (MMP)-9, TGF- $\beta$, and caspase-3. Total RNA was extracted from the frozen tissues using an RNeasy Mini Kit (Qiagen, Valencia, CA, USA) according to the manufacturer's recommendations. The RNA concentration was measured by spectrophotometry in Nanodrop ND-1000. First-strand cDNA was synthesized from total RNA using an M-MLV Reverse Transcriptase Kit (Invitrogen). Relative mRNA levels were measured with a SYBR Green detection system using ABI 7500 real-time PCR (Applied Biosystems, Foster City, CA). All samples were measured in duplicate. The relative level of each gene was calculated as the ratio of the study gene to the control gene (acidic ribosomal phosphoprotein P0 [36 34 ]) and given as the fold change relative to SIL-Sal. The following PCR primers were used: IL-1 $\alpha$ forward 5'-TCA ACC AAA CTA TAT ATC AGG ATG TGG-3' and reverse 5'-CGA GTA GGC ATA CAT GTC AAA TTT TAC-3' 102 bp; IL-1 $\beta$ forward 5'-GTT GAC GGA CCC CAA AAG-3' and reverse 5'GTG CTG CTG CGA GAT TTG-3' 93 bp; IL-1R1 forward 5'-GAG TTA CCC GAG GTC CAG-3' and reverse 5'-GAA GAA GCT CAC GTT GTC-3' 66 bp; IL-1RN forward 5'-AAC CAC CAG GGC ATC ACA TA-3' and reverse 5'-CCT CTT GCC GAC ATG GAA TA-3' 150 bp; IL-10 forward 5'-AGT CCG GCA GAC AAT CGT T-3' and reverse 5'-CCC TGT AAT GGG CTT CCT C-3'; MMP-9 forward 5'-AGT CCG GCA GAC AAT CCT T-3' and reverse 5'-CCC TGT AAT GGG CTT CCT C-3'; caspase-3 forward 5'-TAC CGG TGG AGG CTG ACT-3' and reverse 5'- GCT GCA AAG GGA CTG GAT-3' 104 bp; TGF- $\beta$ forward 5'-ATA CGC CTG AGT GGC TGT C-3' and reverse 5'-GCC CTG TAT TCC GTC TCC T3' 77 bp; $36 \beta 4$ forward 5'-CAA CCC AGT TCT GGA GAA AC-3' and reverse 5'-GTT CTG AGC TCC CAC AGT GA-3' 150 bp.

\section{Detection of Y chromosome DNA}

Quantification of murine $Y$ chromosome in lung tissue was achieved using quantitative real-time PCR at day 60 as previously described [3]. The following PCR primers were used: SRY forward 5'-TCA TCG GAG GGC TAA AGT G-3' and reverse 5'-CAA CCT TCT GCA GTG GGA C-3'; GAPDH forward 5'-CCA CCA ACT GCT TAG CCC-3' and reverse 5'-GAC ACC TAC AAA GAA GGG TCC A-3'.

\section{Statistical analysis}

The normality of the data (Kolmogorov-Smirnov test with Lilliefors' correction) and the homogeneity of variances (Levene median test) were tested. If both conditions were satisfactory, differences between the groups were assessed by two-way analysis of variance ANOVA followed by the Tukey test. The comparison between the SIL-Sal and SIL-Cell groups was performed using the unpaired $t$ test or the Mann-Whitney $U$ test for parametric and non-parametric data, respectively. Data are presented as the mean $\pm \mathrm{SEM}$ or median (25th-75th percentiles) when appropriate. In all tests, the significance level was set at 5\%. Statistical analyses were performed using SigmaPlot 11.0 (Systat Software, Chicago, IL, USA).

\section{Results}

Lung mechanics and engraftment

No significant differences were observed in tidal volume and flow between the groups. The C-Sal and C-Cell groups showed similar values for Est, $\mathrm{L}, \Delta P 1, \mathrm{~L}$, and $\triangle P 2$, L pressures. Higher values for $E$ st, $\mathrm{L}, \triangle P 1$, L, and $\triangle P 2$, L were found for the SIL-Sal group than the C-Sal group $(134 \%, 170 \%$, and $148 \%$, respectively). In the SIL-Cell group, all mechanical parameters were reduced compared with the SIL-Sal group but $\triangle P 1$, L remained higher than for the C-Cell group (Fig. 2A,B). There was no detectable Y chromosome DNA on day 60 in the C-Cell and SIL-Cell groups (data not shown).

\section{Lung inflammation}

In the SIL-Sal group, we observed granulomatous nodules with infiltration of polymorphonuclear and mononuclear cells, mainly macrophages, mixed with proteinaceous material. Moreover, there were increased areas of alveolar collapse, reduced airway lumen, and cell infiltration in the alveolar septa (Fig. 3A). The fractional area of granuloma and the total and differential cell count were reduced after repeated intratracheal therapy with BMDCs (Fig. 3B,C).

Macrophages are the main cells involved in the pathophysiology of silicosis. These cells can be activated by a range of extracellular signals to polarize in M1 macrophages (responsible 
Lopes-Pacheco et al.: Repeated Administration of Stem Cell Prevents Silicosis

Fig. 1. (A) Schematic flow chart and (B) timeline of the study design. C, control; SIL, silicosis. Saline (Sal) and bone marrow-derived cells (BMDCs, Cell) were intratracheally administered on days 15 and 30. Animals were sacrificed on day 60 .

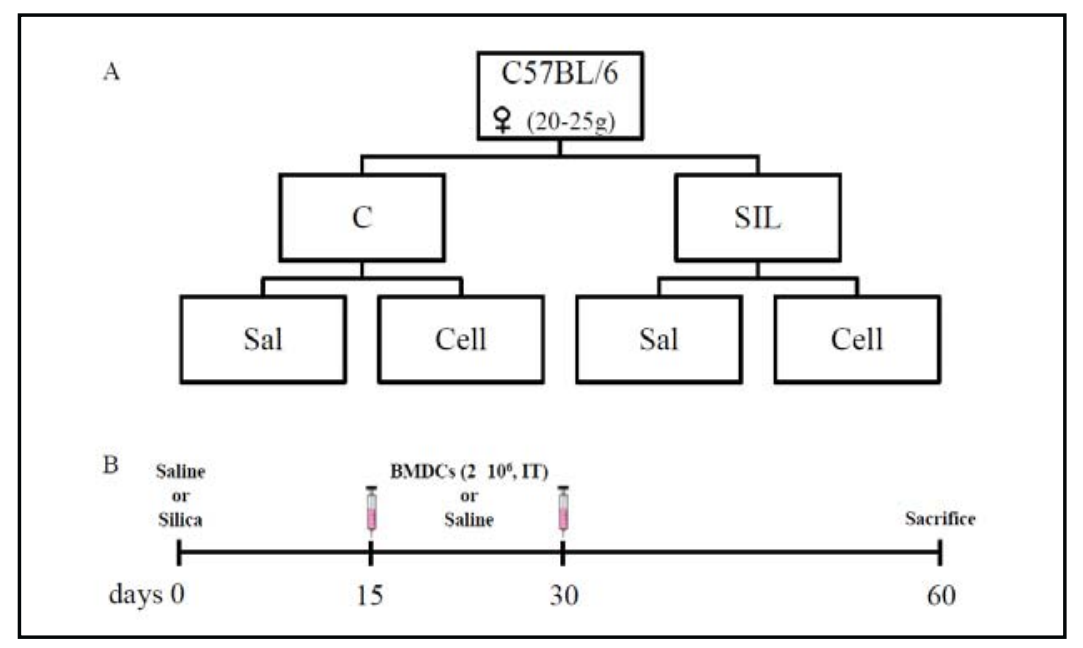

A

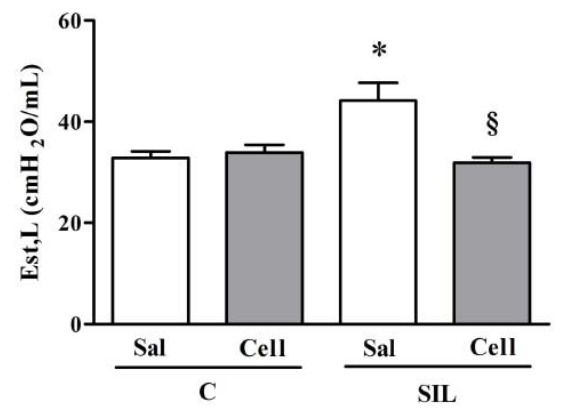

B

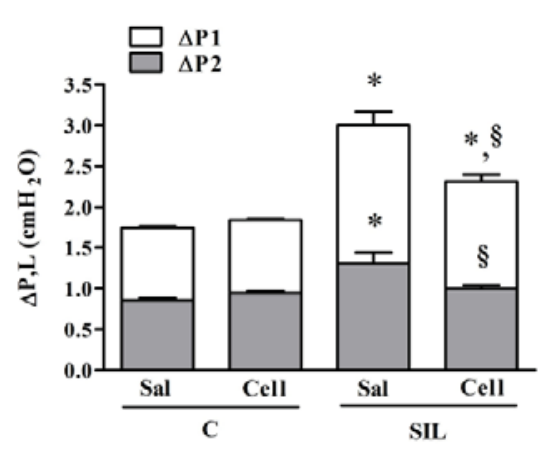

Fig. 2. Lung mechanics. (A) Lung static elastance (Est,L) and (B) resistive pressure $(\triangle P 1, \mathrm{~L})$ and viscoelastic/inhomogeneous pressure $(\triangle P 2, \mathrm{~L})$. C, control; SIL, silicosis. Saline (Sal) and bone marrowderived cells (BMDCs, Cell) were intratracheally (IT) administered on days 15 and 30. Data are presented as means \pm SEM; $n=8$ animals per group. *Significantly different from C-Sal and C-Cell. §Significantly different from SIL-Sal.

for the antimicrobial response and inflammation) or M2 macrophages (responsible for resolving the inflammation and wound repair). The total number of macrophages (MØ) and subpopulations (M1 and M2) were quantified (Fig. 4A-C). In the SIL-Sal group, the number of macrophages was higher in granuloma and alveolar septa compared with the C-Sal group. In SIL-Cell animals, the total number of macrophages and the number of M1 macrophages in alveolar septa and granuloma were lower than in the SIL-Sal group (Fig. 4D-G). No significant difference was observed in the number of M2 macrophages between the SIL-Sal and SIL-Cell groups (Fig. 4H,I).

\section{Expression of $I L-1 \alpha, I L-1 \beta, I L-1 R 1, I L-1 R N, I L-10$, and $M M P-9$}

The level of IL-1 $\beta$, IL-1R1, IL-1RN, IL-1 $\alpha$, IL-10, and MMP-9 mRNA was higher in the SIL-Sal group compared with the C-Sal group. The expression of IL-1 $\beta$ and IL-1R1 reduced after BMDC therapy (Fig. 5A,B), whereas IL-1RN level increased (Fig. 5C). No significant differences were observed in the level of IL-1 $\alpha$, IL-10, and MMP-9 mRNA between the SILSal and SIL-Cell groups (Fig. 5D-F).

\section{Lung remodeling}

The amount of TGF- $\beta$ and type III and I collagen fibers was increased in alveolar septa and granuloma in the SIL-Sal group compared with the C-Sal group. BMDCs reduced mRNA 


\section{Cellular Physiology and Biochemistry}

Fig. 3. (A) Representative photomicrographs of lung parenchyma stained with hematoxylin-eosin (A). Note the presence of granulomas in the SIL groups (*). (B) Quantification of the fractional area of granuloma. Data are presented as median (25th-75th percentiles). (C) Total and differential tissue cellularity in the granuloma. Data are presented as means \pm SEM. C, control; PMN, polymorphonuclear cells; $\mathrm{MN}$, mononuclear cells; SIL, silicosis. Saline (Sal) and bone marrow-derived cells (BMDCs, Cell) were intratracheally (IT) administered on days 15 and 30; $n=8$ animals per group. §Significantly different from SIL-Sal.

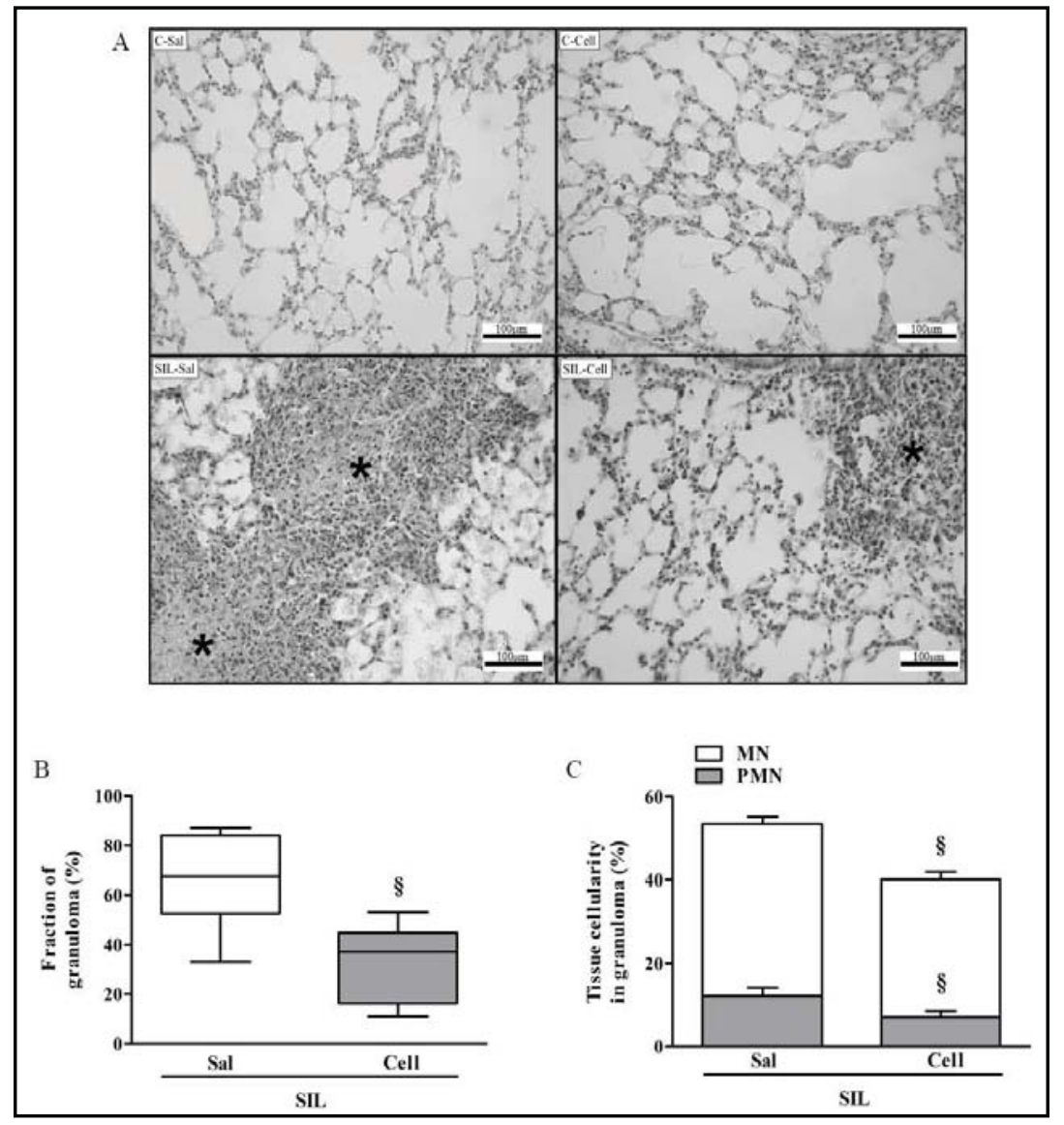

expression of TGF- $\beta$ (Fig. 6) and collagen deposition (types I and III) in granuloma and alveolar septa (Fig. 7). Elastic fiber content was also increased inside the granuloma and alveolar septa in the SIL-Sal group but reduced after BMDC therapy in the alveolar septa (Fig. 8).

\section{Apoptosis}

The number of cells undergoing apoptosis was rare in the C-Sal and C-Cell groups (Fig. 9A). The number of apoptotic cells and the level of caspase-3 mRNA were higher in the SILSal group compared with the C-Sal group (Fig. 9B-D). Repeated administration of BMDCs in silicotic mice reduced apoptosis in the alveolar septa and granuloma, as well as caspase-3 level.

\section{Discussion}

In a previous study, Lassance et al. [11] observed that the early beneficial effects of therapy with BMDCs were ephemeral 60 days after intratracheal instillation of silica particles in murine silicosis. In the current study, we observed that two infusions of BMDCs led to a reduction in collagen and elastic fiber deposition, the total number of macrophages and subpopulation M1 (inflammatory and antimicrobial), as well as the amount of apoptotic cells and the fractional area of granuloma, resulting in improvement in $E s t, \mathrm{~L}, \Delta P 1, \mathrm{~L}$, and $\triangle P 2$, L pressures (Fig. 2). Furthermore, these beneficial effects were independent of the permanence of BMDCs in lung tissue, suggesting a paracrine effect.

A single exposure to crystalline silica can lead to morphofunctional changes after 15 days in a murine model. The functional changes are similar to those observed in the clinical setting $[3,14]$. Silicotic mice showed increased values for $E$ st, L, $\triangle P 1$,L, and $\Delta P 2$, L. The modifications 


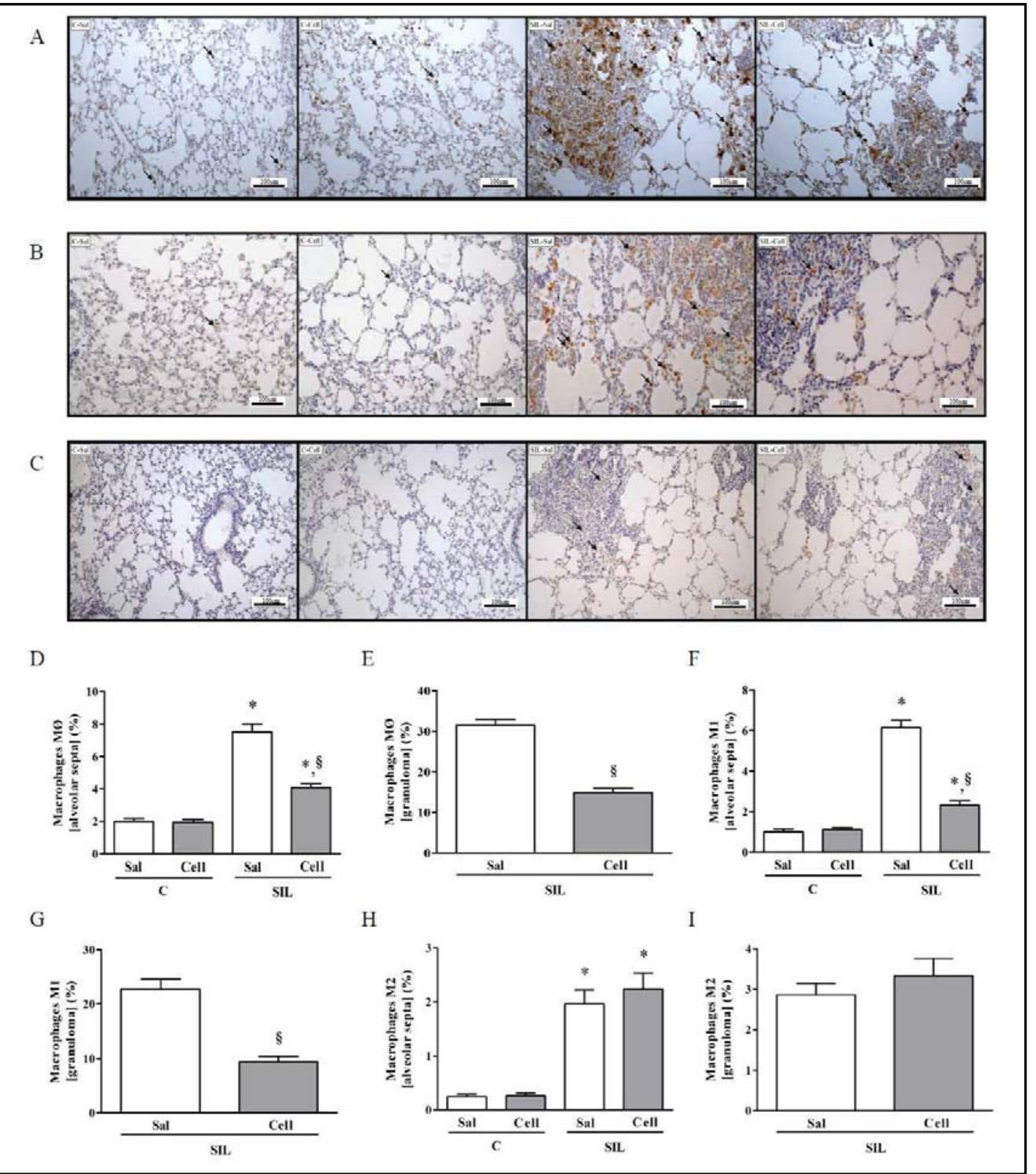

Fig. 4. Representative photomicrographs of lung parenchyma. Immunohistochemistry for: (A) F4/80, (B) iNOS, and (C) arginase-1 antibodies. Note the presence of macrophages (arrows) in the alveolar septa and in the granuloma. Quantification of macrophages $M \emptyset$ in (D) the alveolar septa and (E) the granuloma. Quantification of macrophages M1 in (F) the alveolar septa and (G) the granuloma. Quantification of macrophages M2 in (H) the alveolar septa and (I) the granuloma. C, control; SIL, silicosis. Saline (Sal) and bone marrow-derived cells (BMDCs, Cell) were intratracheally (IT) administered on days 15 and 30. Data are presented as means \pm SEM; $n=8$ animals per group. *Significantly different from C-Sal. $\S$ Significantly different from SIL-Sal.

observed in $E$ st,L and $\triangle P 2$, L could be associated with alveolar collapse, interstitial edema, thickening of alveolar septa, increased number of cells, and the presence of silicotic nodules. The changes in $\triangle P 1, \mathrm{~L}$ may be attributed to intrabronchial cellular infiltration leading to obstruction of the lumen (Figs. 2 and 3 ) in accordance with previous studies on silicotic mice $[3,14-16]$. An increase in the number of macrophages, both in alveolar septa and inside 

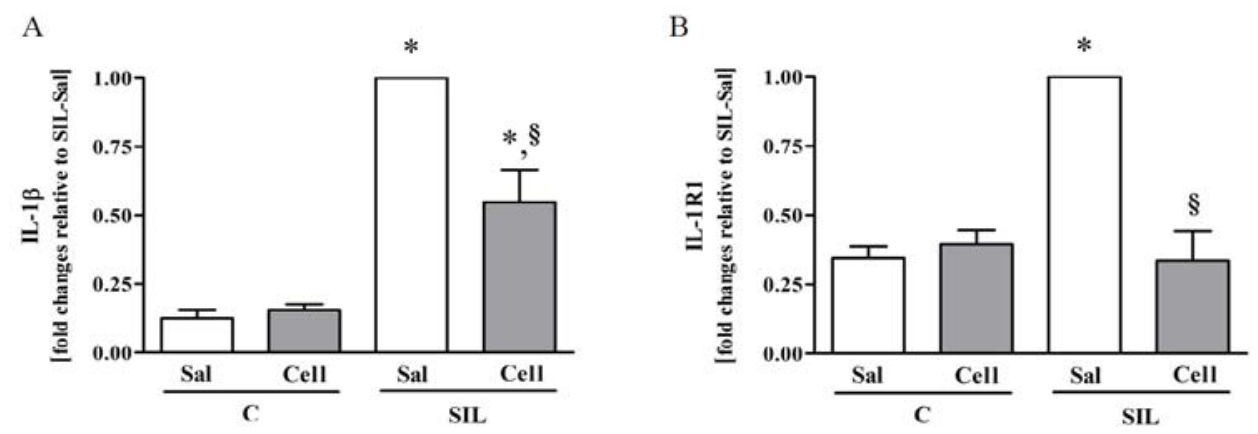

C

D)
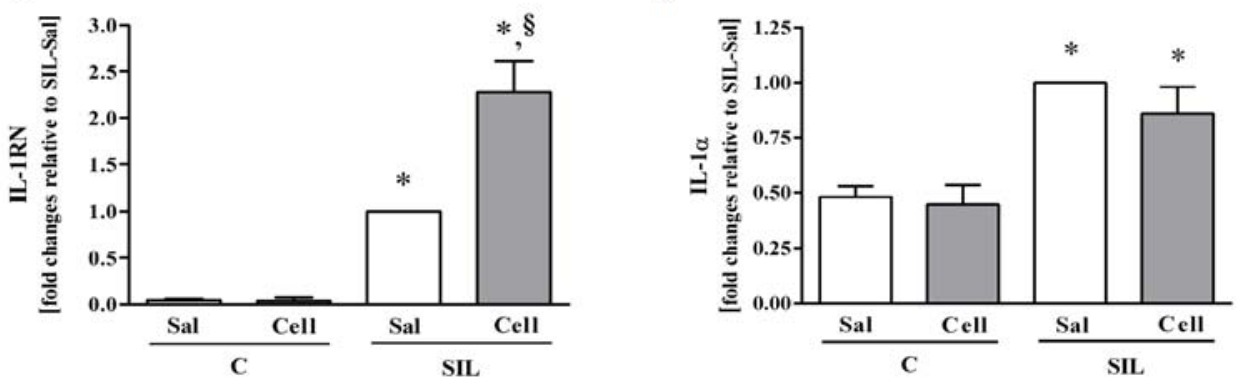

E

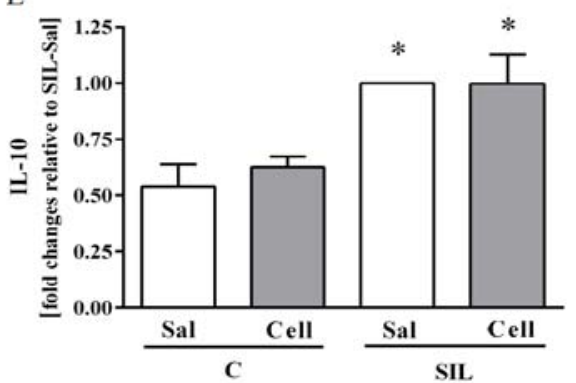

F

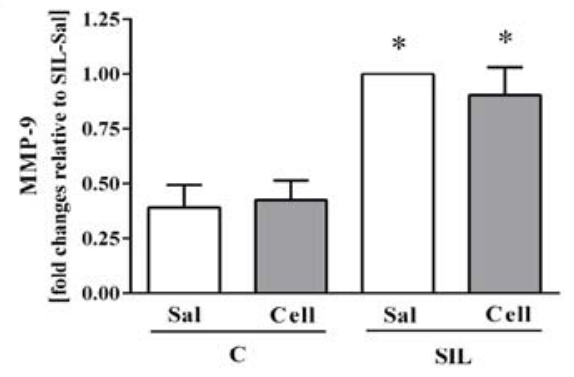

Fig. 5. Real-time reverse transcription PCR analysis of (A) IL-1 $\beta$, (B) IL-1R1, (C) IL-1RN, (D) IL-1 $\alpha$, (E) IL10, and (F) MMP-9. C, control; SIL, silicosis. Saline (Sal) and bone marrow-derived cells (BMDCs, Cell) were intratracheally (IT) administered on days 15 and 30 . Data are presented as means \pm SEM; $n=6$ animals per group. *Significantly different from C-Sal. §Significantly different from SIL-Sal.

granuloma, was found in the SIL-Sal group (Fig. 4). This cell population is one of the key targets in silicosis [2]. The interaction between silica particles and alveolar macrophages can lead to internalization of silica particles by the alveolar macrophages to clear the particles out of the lungs, cell death by apoptosis or activation of cells with the release of proinflammatory cytokines such as IL-1 [1], and the recruitment of inflammatory cells into the lung tissue [17, 18].

IL-1 $\alpha$, IL1- $\beta$, and IL-1RN are members of the IL- 1 family. IL- $1 \alpha$ and IL- $1 \beta$ are agonists and IL-1RN is a naturally occurring receptor antagonist that is produced locally in various tissues in response to infection or inflammation, as an intracellular protein or a secreted form, both of which are capable of competitively inhibiting the local inflammatory effects of IL-1 $[18,19]$. In this context, the increase in the level of IL-1 mRNA in lung tissue was correlated with the development of pulmonary inflammation and fibrosis. However, BMDC therapy minimized the levels of IL-1 $\beta$ and IL-1R1 mRNA (Fig. 5A,B) in concordance with Ortiz et al. [9] and Levis et al. [20], who observed a downregulation of both after infusion of 


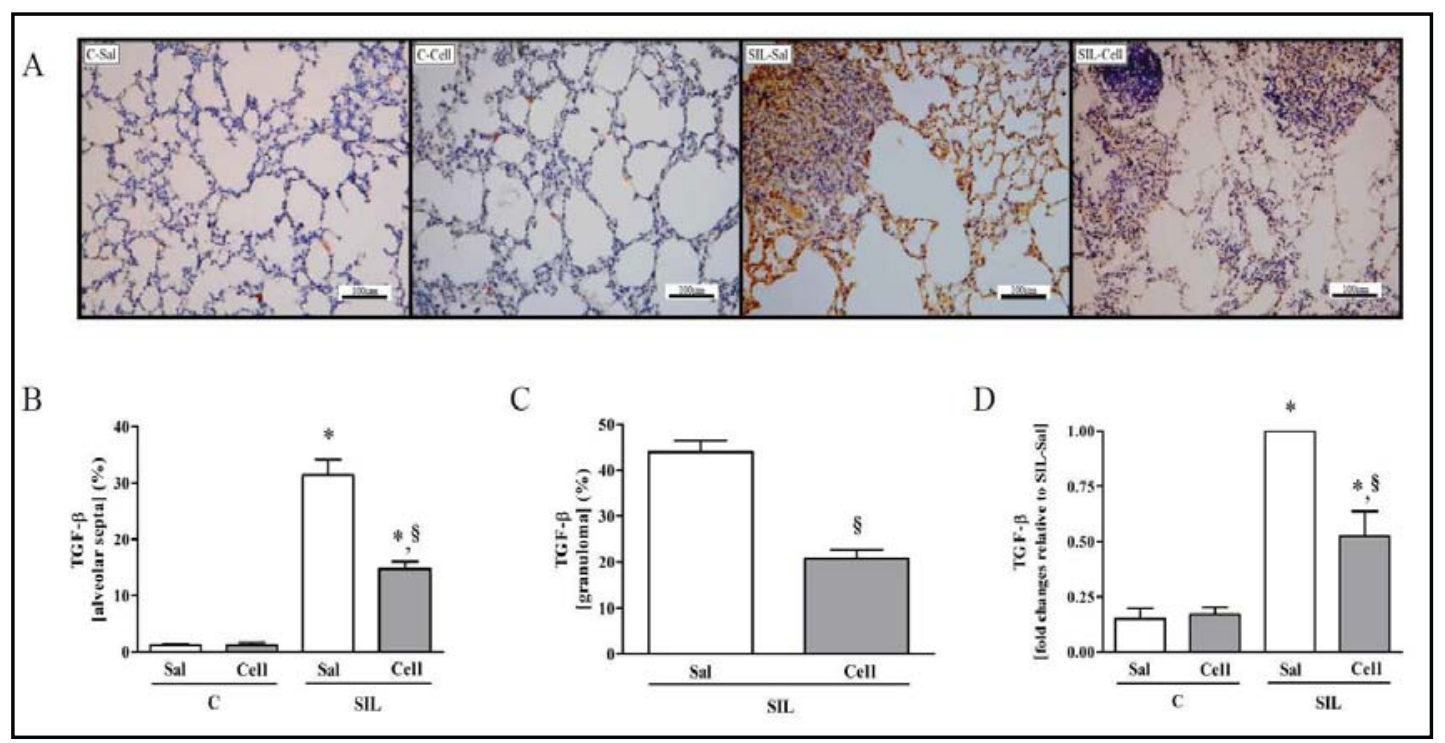

Fig. 6. Representative photomicrographs of lung parenchyma. Immunohistochemistry for TGF- $\beta$ antibody (A). Quantification of TGF- $\beta$ in (B) the alveolar septa and (C) the granuloma. Data are presented as means \pm SEM; $n=8$ animals per group. Real-time reverse transcription PCR analysis of TGF- $\beta$ (D). Data are presented as means \pm SEM; $n=6$ animals per group. C, control; SIL, silicosis. Saline (Sal) and bone marrowderived cells (BMDCs, Cell) were intratracheally (IT) administered on days 15 and 30. *Significantly different from C-Sal. §Significantly different from SIL-Sal.

BMDCs in experimental lung fibrosis. The high levels of IL-1RN induced after BMDC therapy (Fig. 5C) may have a crucial role in promoting antiinflammatory and antifibrotic responses similar to those shown by Ortiz et al. [9] after infusion of mesenchymal cells in a bleomycin model. Previous studies have shown that IL-10 may be involved in the process of fibrosis in pulmonary silicosis $[21,22]$. Furthermore, an increase in MMP-9 activity is reported in silica-induced lung injury $[23,24]$. Two infusions of BMDC were not able to act on the levels of IL-1 $\alpha$, IL-10, and MMP-9 mRNA (Fig. 5D-F). Our findings support the hypothesis that the increase in IL-1RN had a decisive role in the beneficial effect of treatment with BMDC in a murine model of silicosis.

Concomitant with the inflammatory process, the presence of silica in lung tissue also triggered apoptosis $[16,25]$, with increased expression of caspase-3 $[17,26]$. The increase in apoptotic cells may be associated with release of mediators to recruit cells and maintain the inflammatory process. In this context, repeated infusion of BMDCs reduced the number of apoptotic cells and the level of caspase-3 (Fig. 9) and the level of inflammation, decreasing the number of macrophages (Fig. 4), which plays a central role in the pathophysiology of silicosis. A decrease in the number of apoptotic cells in the SIL-Cell group is seen in a series of disease models after infusion of BMDCs (mononuclear, hematopoietic, or mesenchymal cells) [27-32].

The lower number of macrophages in alveolar septa and silicotic nodules after BMDC therapy may be associated with the decrease in the level of IL-1 $\beta$ mRNA (Fig. 5A). This cytokine plays a key role in the development of silicosis by regulating the mediators that are responsible for the persistent inflammation and development of fibrosis. Furthermore, IL-1 $\beta$ has been implicated in fibroblast activation and collagen deposition [33]. As already demonstrated in other models of lung inflammation and fibrosis [10], BMDCs were able to prevent an increase in the amount of TGF- $\beta$ in lung tissue as well as TGF- $\beta$ mRNA after instillation of silica [3]. TGF- $\beta$ regulates a wide variety of cellular processes including cell growth, apoptosis, differentiation, migration, and extracellular matrix production [34]. In our work, the amount of TGF- $\beta$ in alveolar septa and granuloma and TGF- $\beta$ mRNA was reduced 


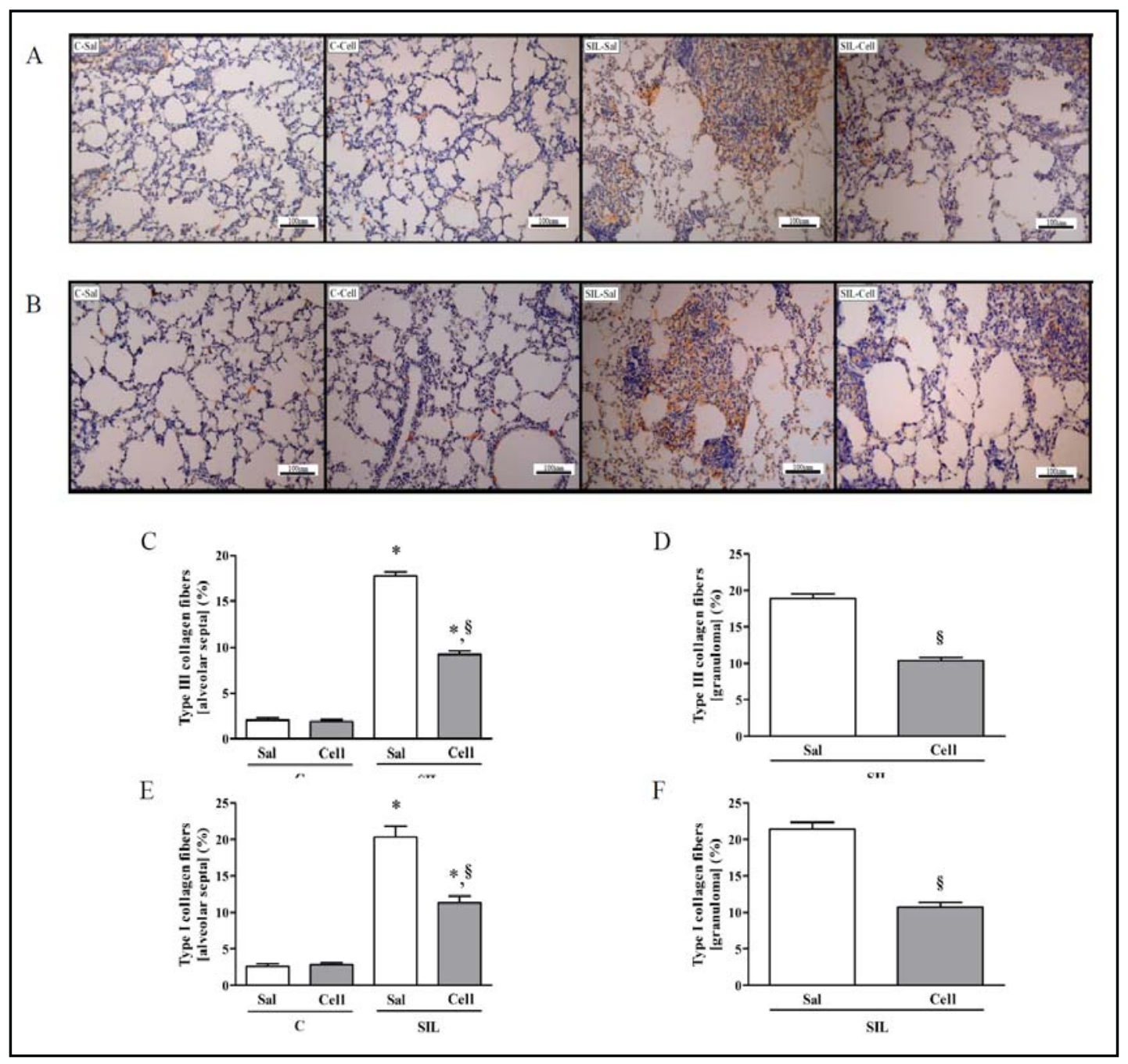

Fig. 7. Representative photomicrographs of lung parenchyma. Immunohistochemistry for type III (A) and type I (B) collagen fiber. Quantification of collagen type III in (C) the alveolar septa and (D) the granuloma. Quantification of collagen type I in (D) the alveolar septa and (F) the granuloma. C, control; SIL, silicosis. Saline (Sal) and bone marrow-derived cells (BMDCs, Cell) were intratracheally (IT) administered on days 15 and 30. Data are presented as means \pm SEM; $n=8$ animals per group. *Significantly different from C-Sal. $\S$ Significantly different from SIL-Sal.

in silicotic mice treated with two infusions of BMDCs (Fig. 6). The increased expression of TGF- $\beta$ may be associated with apoptosis and collagen deposition in the SIL-Sal group, which could influence fibroblast cell migration, proliferation, and the remodeling process. In this context, the SIL-Cell group showed a decrease in the deposition of type III and I collagen fibers in alveolar septa and granuloma (Fig. 7). Besides the increased deposition of collagen in the extracellular matrix, the change in the amount of elastic fibers is an important factor involved in lung remodeling in silica-induced lung injury $[14,35]$. The infusion of BMDCs in the SIL group was able to reduce elastic fiber deposition in alveolar septa (Fig. 8).The decrease in the inflammatory process and deposition of extracellular matrix elements led to an improvement in respiratory function because they allowed remodeling of the lung parenchyma favoring expansion of alveoli.

Despite the positive effects observed, our study had some limitations: (1) the study was done using a model of silicosis; we do not know the effects of this therapy on different degrees of lung injury or others models of fibrosis. (2) We chose an end point of 60 days after 


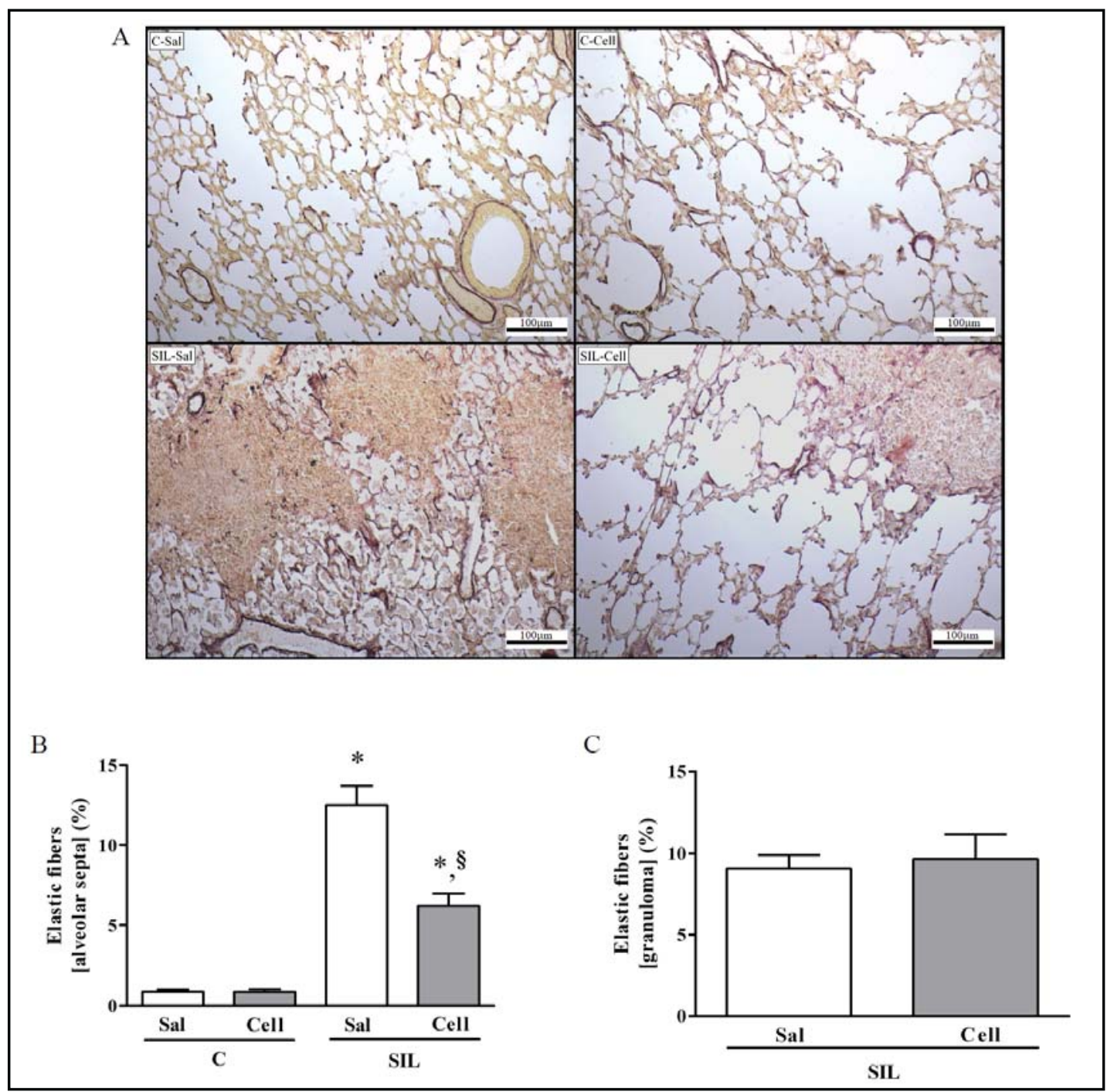

Fig. 8. Representative photomicrographs of lung parenchyma stained with Weigert's resorcin-fuchsin method with oxidation (A). Quantification of elastic fibers in the alveolar septa (B) and the granuloma (C). C, control; SIL, silicosis. Saline (Sal) and bone marrow-derived cells (BMDCs, Cell) were intratracheally (IT) administered on days 15 and 30 . Data are presented as means \pm SEM; $n=8$ animals per group. *Significantly different from C-Sal. §Significantly different from SIL-Sal.

administration of silica particles to compare the results with previous work [11] and better evaluate therapy with BMDC on lung remodeling. However, it would be interesting to study later time points because silicosis is a chronic irreversible disease. (3) Some reports [36, 37] have suggested a standard definition of bone marrow mesenchymal cells: (a) can adhere to plastic in culture conditions, (b) can be differentiated in vitro in adipocytes, osteocytes, and chondrocytes; and (c) surface markers CD11b or CD14, CD19 or CD79a, CD34, CD45, and HLA-DR are absent; CD73, CD90, and CD105 are present.

\section{Conclusion}

The effects promoted by two doses of BMDCs instilled intratracheally seem to enhance the temporary mechanisms of tissue protection already seen after one dose, and provide further information about the clinical applications of cell therapy. The sustained beneficial 


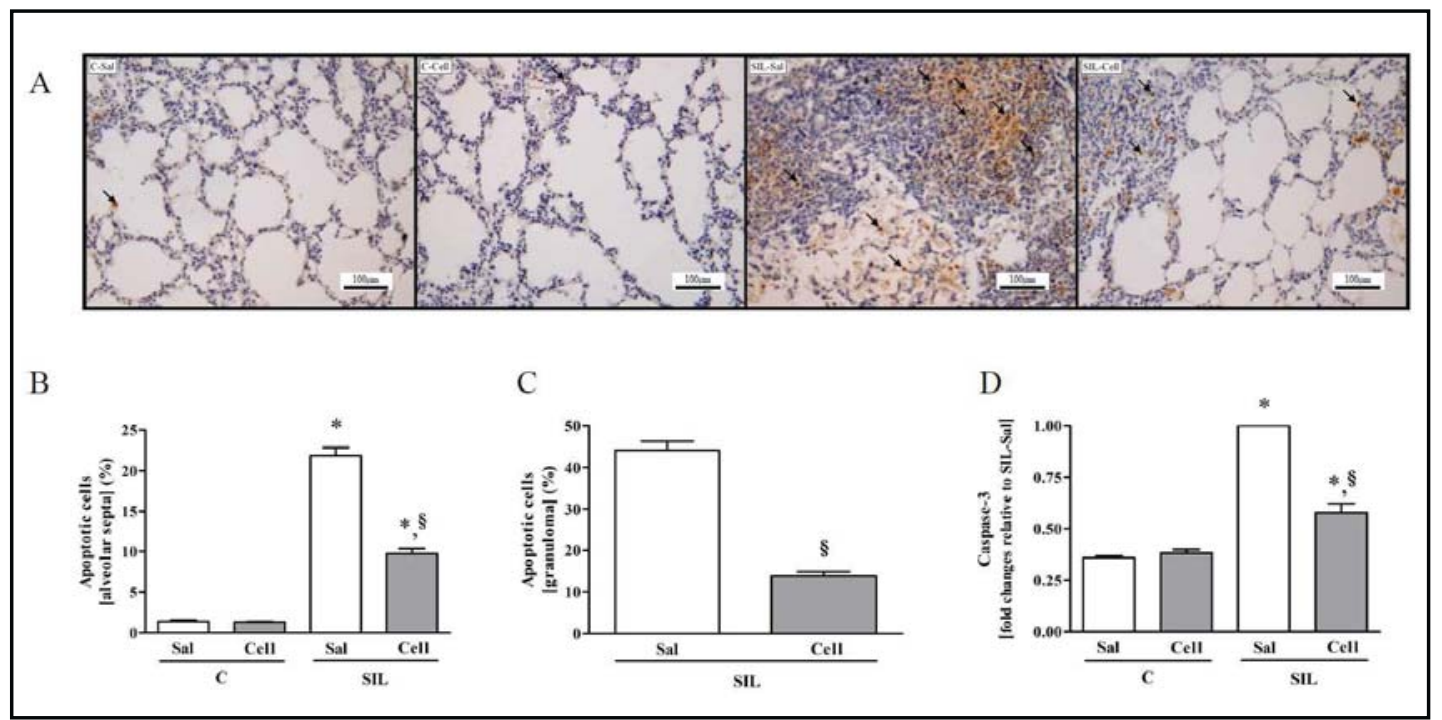

Fig. 9. Representative photomicrographs of lung parenchyma stained with TUNEL (A). Note the presence of apoptotic cells (arrows) in the alveolar septa and in the granuloma. Quantification of apoptotic cells in (B) the alveolar septa and (C) the granuloma. Data are presented as means \pm SEM; $n=8$ animals per group. Real-time reverse transcription PCR analysis of caspase-3 (C). Data are presented as means \pm SEM; $n=6$ animals per group. C, control; SIL, silicosis. Saline (Sal) and bone marrow-derived cells (BMDCs, Cell) were intratracheally (IT) administered on days 15 and 30. *Significantly different from C-Sal. §Significantly different from SIL-Sal.

effects of cell therapy through repeated administration of BMDCs may be independent of engraftment of bone marrow cells into the lung, but may be mediated by an increase in the level of IL1-RN promoting downregulation of inflammatory and fibrogenic responses to silica-induced lung injury.

\section{Acknowledgments}

The authors would like to express their gratitude to Mrs Lorna O'Brien for her assistance in editing the manuscript, Mr Andre Benedito da Silva for animal care, Mrs Ana Lucia Neves da Silva for her help with microscopy. This study was supported by the Centers of Excellence Program (PRONEX-FAPERJ), Brazilian Council for Scientific and Technological Development (CNPq), Rio de Janeiro State Research Supporting Foundation (FAPERJ), National Institute of Science and Technology of Drugs and Medicine (INCT-INOFAR), and Coordination for the Improvement of Higher Level Personnel (CAPES).

\section{References}

1 Srivastava KD, Rom WN, Jagirdar J, Yie TA, Gordon T, Tchou-Wong KM: Crucial role of interleukin-1beta and nitric oxide synthase in silica-induced inflammation and apoptosis in mice. Am J Respir Crit Care Med 2002;165:527-533.

2 Huaux F: New developments in the understanding of immunology in silicosis. Curr Opin Allery Clin Immunol 2007;7:168-173.

3 Maron-Gutierrez T, Castiglione RC, Xisto DG, Oliveira MG, Cruz FF, Peçanha R, Carreira-Junior H, Ornellas DS, Moraes MO, Takiya CM, Rocco PR, Morales MM: Bone marrow-derived mononuclear cell therapy attenuates silica-induced lung fibrosis. Eur Respir J 2011;37:1217-1225. 


\section{Cellular Physiology and Biochemistry}

Cell Physiol Biochem 2013;32:1681-1694

\begin{tabular}{l|l}
\hline DOI: $10.1159 / 000356603$ & (C) 2013 S. Karger AG, Basel
\end{tabular}

Lopes-Pacheco et al.: Repeated Administration of Stem Cell Prevents Silicosis

4 Leung CC, Yu IT, Chen W: Silicosis. Lancet 2012;379:2008-2018.

-5 Abreu SC, Antunes MA, Pelosi P, Morales MM, Rocco PR: Mechanisms of cellular therapy in respiratory diseases. Intensive Care Med 2011;37:1421-1431.

-6 Rojas M, Xu J, Woods CR, Mora AL, Spears W, Roman J, Brigham KL: Bone marrow-derived mesenchymal stem cells in repair of the injured lung. Am J Respir Cell Mol Biol 2005;33:145-152.

7 Spees JL, Pociask DA, Sullivan DE, Whitney ML, Lasky JA, Prockop DJ, Brody AR: Engraftment of bone marrow progenitor cells in a rat model of asbestos-induced pulmonary fibrosis. Am J Respir Crit Care Med 2007;176:385-394.

- Kotton DN, Ma BY, Cardoso WV, Sanderson EA, Summer RS, Williams MC, Fine A: Bone marrow-derived cells as progenitors of lung alveolar epithelium. Development 2001;28:5181-5188.

-9 Ortiz LA, Dutreil M, Fattman C, Pandey AC, Torres G, Go K, Phinney DG: Interleukin 1 receptor antagonist mediates the anti-inflammatory and antifibrotic effect of mesenchymal stem cells during lung injury. Proc Natl Acad Sci U S A 2007;104:11002-11007.

-10 Cruz FF, Antunes MA, Abreu SC, Fujisaki LC, Silva JD, Xisto DG, Maron-Gutierrez T, Ornellas DS, Sá VK, Rocha NN, Capelozzi VL, Morales MM, Rocco PR: Protective effects of bone marrow mononuclear cell therapy on lung and heart in an elastase-induced emphysema model. Respir Physiol Neurobiol 2012;182:26-36.

-11 Lassance RM, Prota LF, Maron-Gutierrez T, Garcia CS, Abreu SC, Pássaro CP, Xisto DG, Castiglione RC, Carreira H Jr, Ornellas DS, Santana MC, Souza SA, Gulfillen B, Fonseca LM, Rocco PR, Morales MM: Intratracheal instillation of bone marrow-derived cell in an experimental model of silicosis. Respir Physiol Neurobiol 2009;169:227-233.

-12 Bates JH, Decramer M, Chartrand D, Zin WA, Boddener A, Milic-Emili J: Volume-time profile during relaxed expiration in the normal dog. J Appl Physiol 1985;59:732-737.

13 Weibel ER: Morphometry: stereological theory and practical methods; in Gil J (ed): Models of Lung Disease Microscopy and Structural Methods. New York, Marcel Dekker, 1990, pp 199-247.

14 Faffe DS, Silva GH, Kurtz PM, Negri EM, Capelozzi VL, Rocco PR, Zin WA: Lung tissue mechanics and extracellular matrix composition in a murine model of silicosis. J Appl Physiol 2001;90:1400-1406.

-15 Borges VM, Falcão H, Leite-Júnior JH, Alvim L, Teixeira GP, Russo M, Nóbrega AF, Lopes MF, Rocco PM, Davidson WF, Linden R, Yagita H, Zin WA, DosReis GA: Fas ligand triggers pulmonary silicosis. J Exp Med 2001;194:155-164.

-16 Borges VM, Lopes MF, Falcão H, Leite-Júnior H, Rocco PR, Davidson WF, Linden R, Zin WA, DosReis GA: Apoptosis underlies immunopathogenic mechanisms in acute silicosis. Am J Respir Cell Mol Biol 2002;27:78-84.

17 Rimal B, Greenberg AK, Rom WN: Basic pathogenetic mechanisms on silicosis: current understanding. Curr Opin Pulm Med 2005;11:169-173.

18 Greenberg MI, Waksman J, Curtis J: Silicosis: a review. Dis Mon 2007;53:394-416.

19 Arend WP, Gabay C: Physiologic role of interleukin-1 receptor antagonist. Arthritis Res 2000;2:245-248.

20 Levis J, Loi R, Butnor KJ, Vacek P, Steele C, Mossman BT, Weiss DJ: Decreased asbestos-induced lung inflammation and fibrosis after radiation and bone marrow transplant. Am J Respir Cell Mol Biol 2008;38:16-25.

21 Huaux F, Louahed J, Hudspith B, Meredith C, Delos M, Renauld JC, Lison D: Role of interleukin-10 in the lung response to silica in mice. Am J Respir Mol Biol 1998;18:51-59.

22 Barbarin V, Arras M, Misson P, Delos M, McGarry B, Phan SH, Lison D, Huaux F: Characterization of the effect of interleukin-10 on silica-induced lung fibrosis in mice. Am J Respir Cell Mol Biol 2004;31:78-85.

23 Ishihara Y, Nishikawa T, Iijima H, Matsunaga K: Expression of matrix metalloproteinase, tissue inhibitor of metalloproteinase and adhesion molecules in silicotic mice with tumor metastasis. Toxicol Lett 2003;142:71-75.

-24 Scabilloni JF, Wang L, Antonini JM, Roberts JR, Castranova V, Mercer RR: Matrix metalloproteinase induction in fibrosis and fibrotic nodules formation due to silica inhalation. Am J Physiol Lung Cell Mol Physiol 2005;288:L709-L717.

25 Lalmanach G, Diot E, Godat E, Lecaille F, Hervé-Grépinet V: Cysteine cathepsins and caspases in silicosis. Biol Chem 2006;387:867-870.

26 Shen HM, Zhang Z, Zhang QF, Ong CN: Reactive oxygen species and caspase activation mediate silicainduced apoptosis in alveolar macrophages. Am J Physiol Lung Cell Mol Physiol 2001;280:L10-L17. 
27 Sheng QS, Chen WB, Lin JJ, Liu FL, Chen DZ: Effects of autologous bone marrow mononuclear cells implantation on cholangiocytes apoptosis in model of intrahepatic ischemic type biliary lesion in rabbits. Transplant Proc 2012;44:1435-1438.

-28 Mo SJ, Zhong Q Zhou YF, Deng DB, Zhang XQ: Bone marrow-derived mesenchymal stem cells prevent the apoptosis of neuron-like PC12 cells via erythropoietin expression. Neurosci Lett 2012;522:92-97.

29 Rosenberg S, Zhang H, Zhang J: FADD deficiency impairs early hematopoiesis in the bone marrow. J Immunol 2012;186:203-213.

-30 Kanazawa H, Fujimoto Y, Teratani T, Iwasaki J, Kasahara N, Negishi K, Tsuruyama T, Uemoto S, Kobayashi E: Bone marrow-derived mesenchymal stem cells ameliorate hepatic ischemia reperfusion injury in a rat model. PLoS One 2011;6:e19195.

-31 Lovell MJ, Yasin M, Lee KL, Cheung KK, Shintani Y, Leung KY, Takahashi K, Kapoor A, Yagoob MM, Suzuki K, Lythgoe MF, Martin J, Munroe PB, Thiemermann C, Mathur A: Bone marrow mononuclear cells reduce myocardial reperfusion injury by activating the PI3K/Akt survival pathway. Atherosclerosis 2010;213:6776.

32 Barreira AL, Takiya CM, Castiglione RC, Maron-Gutierrez T, Barbosa CM, Ornellas DS, Verdoorn KS, Pascarelli BM, Borojevic R, Einicker-Lamas M, Leite M Jr, Morales MM, Vieyra A: Bone marrow mononuclear cells attenuate interstitial fibrosis and stimulate the repair of tubular epithelial cells after unilateral ureteral obstruction. Cell Physiol Biochem 2009;24:585-594.

-33 Mariani TJ, Roby JD, Mecham RP, Parks WC, Crouch E, Pierce RA: Localization of type I procollagen gene expression in silica-induced granulomatous lung disease and implication of transforming growth factorbeta as a mediator of fibrosis. Am J Pathol 1996;148:151-164.

-34 Rahimi RA, Leof EB: TGF-beta signaling: a tale of two responses. J Cell Biochem 2007;102: 591-608.

- 35 Mariani TJ, Crouch E, Roby JD, Starcher B, Pierce RA: Increased elastin production in experimental granulomatous lung disease. Am J Pathol 1995;147:988-1000.

- 36 Dominici M, Le Blanc K, Mueller I, Slaper-Cortenbach I, Marini F, Krause D, Deans R, Keating A, Prockop DJ, Horwitz E: Minimal criteria for defining multipotent mesenchymal stromal cells. The International Society for Cellular Therapy position statement. Cytotherapy 2006;8:315-317.

- 37 Da Silva Meireles L, Caplan AI, Nardi NB: In search of the in vivo identify of mesenchymal stem cells. Stem cells 2008;26:1307-1314. 